Revista do SELL

v. $4, n^{\circ} .2$

ISSN: $1983-3873$

\title{
A PRESENÇA DO CIÚME NA OBRA DE ITALO SVEVO
}

\section{THE PRESENCE OF JEALOUSY IN THE WORK OF ITALO SVEVO}

\author{
Ivair Carlos Castelan \\ Universidade de São Paulo
}

RESUMO: O principal objetivo deste trabalho é realizar uma leitura atenta que demonstre a presença do ciúme nos romances de Italo Svevo: Uma vida (1892), Senilidade (1898) e A Consciência de Zeno (1923). Partindo da ordem de publicação de cada obra, pretendese demonstrar como o ciúme é importante na constituição da trama das respectivas narrativas. Desse modo, a análise embasar-se-á especialmente na teoria do filósofo francês, René Girard, presente em sua obra Mentira Romântica e Verdade Romanesca.

PALAVRAS-CHAVE: Ciúme; Italo Svevo; Literatura Italiana; Triângulos Amorosos.

ABSTRACT: The main aim of this work is to perform a careful reading which shows the presence of jealousy in the novels of Italo Svevo: Uma vida (1892), Senilidade (1898) and A Consciência de Zeno (1923). Based on the publishing order of each novel, it is intended to demonstrate how jealousy is important in the plot foundation in the aforementioned novels. The analysis will be mainly based in the theory of the French philosopher René Girard, present in his work Mentira Romântica e Verdade Romanesca.

KEY-WORDS: Jealousy; Italo Svevo; Italian Literature; Love Triangles.

\section{INTRODUÇÃO}

Nascido no ano de 1861 em Trieste, nordeste da Itália, Italo Svevo é considerado, hoje, um dos maiores romancistas do século XX, precursor de uma narrativa tida como de vanguarda, cujo tempo objetivo, cronológico, é substituído pelo tempo do "eu", da consciência inquieta de seus personagens.

Apresentando uma narrativa riquíssima, aberta a visões e interpretações diversas, julgamos fundamental destacar que propomos uma leitura de seus três romances: Uma vida (1892), Senilidade (1898) e A consciência de Zeno (1923), que privilegie os próprios textos e que permita desvelar as relações amorosas, desnudando o ciúme intrínseco aos protagonistas das respectivas narrativas.

De acordo com Teresa de Lauretis, a narrativa do início século XX abandona a representação de uma realidade objetiva, adotando a interpretação de uma realidade 


\section{Revista do SELL \\ v. $4, n^{\circ} .2$ \\ ISSN: $1983-3873$}

subjetiva, interior. Assim, teríamos o que a estudiosa chama de romances do eu, ou seja, um romance cuja temática girará em torno das problemáticas que circundam o eu mais profundo do homem (LAURETIS, 1976, p.156).

Entre tais problemáticas destacamos as relações amorosas vividas pelos protagonistas dos romances, discriminados anteriormente; tais personagens sempre serão alvo de um sentimento amargo, o ciúme. Assim, Alfonso Nitti, protagonista do primeiro romance de Svevo, em meio a suas indecisões, ainda que não aceite, sente ciúmes de Annetta. E talvez por medo desse sentimento não consiga entregar-se a sua paixão.

Emilio Brentani, protagonista do segundo romance, ao contrário, inicia um relacionamento casual, sem qualquer vínculo afetivo, como ele mesmo deixa claro no início da narrativa, com a bela Angiolina Zarri, contudo com o desenrolar da história tornase evidente seu envolvimento com a moça. Emilio se apaixonará perdidamente pela senhorita Zarri, contudo também não conseguirá viver plenamente essa paixão, pois será corroído por um ciúme "doentio".

No terceiro e mais conhecido romance de Svevo, A Consciência de Zeno, o ciúme é pintado com cores mais leves. Talvez isso se deva em parte, ao amadurecimento do narrador. Dos três protagonistas, Zeno Cosini é o que, aparentemente, "relaciona-se" melhor com a questão do ciúme.

Elemento essencial na narrativa dos três romances, o ciúme é consolidado com a constituição do que podemos chamar de triângulo amoroso que, por sua vez, será peça fundamental nos relacionamentos afetivos que se concretizam apenas na presença de um terceiro elemento, um mediador entre o sujeito que deseja e o seu objeto desejado.

\section{NARRATIVA SVEVIANA: UM OLHAR AO CIÚME}

A palavra ciúme, segundo o psicanalista e filósofo italiano Sergio Benvenuto, porta consigo certa ambiguidade, pois pode se referir ao ciúme propriamente dito, mas também à inveja. Os limites que separam os dois sentimentos é bastante tênue. De acordo com Benvenuto a inveja é sempre dual, implicando consequentemente duas partes: o invejoso 


\section{Revista do SELL}

v. $4, n^{\circ} .2$

ISSN: $1983-3873$

e o invejado. Já o ciúme implica em um triângulo formado pelo eu-cimento, o outro e o rival (BENVENUTO, 2001, p.11). À esteira de Benvenuto, Melanie Klein afirma que a inveja pressupõe a relação do indivíduo com uma só pessoa; em contrapartida o ciúme, segundo a crítica, apresenta sua base na inveja, mas envolve uma relação com, pelo menos, duas pessoas ${ }^{1}$ (KLEIN, 1991, p.212). Outra diferença entre tais sentimentos é defendida por Bordelois que afirma que enquanto o invejoso deseja algo que não possui, o ciumento teme ser despojado daquilo que acredita possuir (BORDELOIS, 2007, p.119).

Em contrapartida às definições de inveja propostas por Benvenuto e Klein, o filósofo frânces, René Girad, não vê diferenças entre esses dois sentimentos. Para ele, tanto o ciúme quanto a inveja pressupõem uma tripla presença: presença do objeto, presença do sujeito e presença daquele que é alvo do ciúme ou da inveja. Tais sentimentos, ou "defeitos" como Girard os denomina são portanto triangulares (GIRARD, 1965, p.14)

Micaela Pretolani Claar ressalta que o amor é fundamental para descrever o mundo interior dos personagens svevianos, bem como a relação deles com a vida (CLAAR, 1986, p.123). Assim, amor, paixão, angústia, tristeza, inveja e ciúme destacam-se nas histórias vividas pelos personagens dos três romances. $\mathrm{O}$ amor é importante como afirma a crítica para o conhecimento do mundo interior dos personagens, contudo uma análise enviesada a partir do ciúme permite-nos afirmar que os protagonistas, em especial Alfonso Nitti e Emilio Brentani, demonstram uma grande dificuldade, ou até mesmo incapacidade, de entrega a uma experiência amorosa mais plena. Desse modo, o ciúme atuaria como o principal obstáculo à concretização dessas paixões.

Essa incapacidade de entrega não só à vivência do amor, mas também à vida, remete ainda a um tema recorrente na obra sveviana, ou seja, a inettitudine ${ }^{2}$ de seus personagens, da qual não trataremos neste trabalho, pois isso nos desviaria do recorte a que pretendemos analisar. Nosso foco é a sondagem da presença do ciúme nas três narrativas.

\footnotetext{
${ }^{1}$ Não abordaremos no presente trabalho as relações entre inveja e ciúme, uma vez que nosso foco é apenas o segundo elemento. Acerca da tênue diferença que separa esses dois sentimentos é interessante consultar KLEIN, Melanie. Inveja e gratidão. In: Inveja e gratidão e outros trabalhos (1946-1963); tradução da 4⿳亠丷厂 edição inglesa Belinda H. Mandelbaum et al. Rio de Janeiro: Imago, 1991.

${ }^{2}$ A figura do personagem inetto é recorrente na obra de Svevo, e representa o indivíduo que não é capaz de adaptar-se à vida em sociedade, seguindo as regras e convenções sociais, mas que também não consegue ter nenhuma atitude de rebeldia e confronto com tais convenções.
} 


\section{Revista do SELL}

v. $4, n^{\circ} .2$

ISSN: $1983-3873$

Ainda que por modos diferentes, as diversas teorias que discorrem sobre o ciúme convergem em um ponto, ou seja, no "caráter" triplo desse sentimento, cuja figura geométrica que melhor o representa é, sem dúvida, o triângulo. O ciúme, dessa forma, implica três lados, ou como o definiu Barthes é "uma equação de três termos (BARTHES, 1981, p.55), sendo que o ser amado é desejado porque um outro ou outros mostram ao sujeito que ele é desejável; por mais especial que seja, o desejo amoroso é descoberto por indução" (BARTHES, 1981, p.127).

Greimas também insiste nesse caráter triplo quando fala sobre o ciúme. Segundo ele, tal sentimento pode ser visto como uma "paixão intersubjetiva que comporta, ao menos potencialmente, três atores: o ciumento, o objeto, o rival” (GREIMAS, 1993, p.171). Assim, "todas as definições [para o ciúme] atestam direta ou indiretamente, a existência de um anti-sujeito que ameaça sancionar o que já sancionou" (GREIMAS, 1993, p.173).

Jorge Coli, ao discorrer sobre Otelo de W. Shakespeare, ressalta que o ciúme atua do exterior (COLI, 2009, p.261), ou seja, é necessário o que René Girard chama de mediador para instigar o desejo do sujeito pela amada e assim "dar vida" ao triângulo amoroso.

Nesse contexto, amor e ciúme formam um par que não pode ser desfeito, constituindo-se nos lados opostos de uma mesma moeda, uma vez que o primeiro sentimento estabelece uma relação de dependência com o segundo, a fim de garantir "a promessa do outro, na presença real ou imaginária do rival. Não importa: o ciúme assegura que o objeto do meu desejo também é desejado por outros", consequentemente meu desejo tende a aumentar (ROCHA, 2009, p.17).

Conforme a teoria postulada por René Girard, toda relação amorosa é triangular. O terceiro elemento que compõe um dos vértices do triângulo pode ser chamado de mediador. É importante deixar claro que, segundo a teoria de Girard, o mediador é o responsável por provocar determinado sentimento no sujeito desejante. Tal sentimento pode ser de desejo, de ódio, de inveja, de amor ou de ciúme. Ainda conforme o teórico francês, "o sujeito desejante necessita de um modelo que apoie sua decisão; nunca se atreve a desejar por conta própria" (GIRARD, 2009, p.400).

Assim, Alfonso Nitti, Emilio Brentani e Zeno Cosini precisam saber que suas "amadas" são desejadas por outros homens. Segundo João Cezar de Castro Rocha, em 


\section{Revista do SELL \\ v. $4, n^{\circ} .2$ \\ ISSN: $1983-3873$}

A primeira pedra de uma Catedral, que introduz o texto de René Girard, "os escritores que tematizam a necessária presença do mediador permitem que se vislumbre" a verdade romanesca, em contrapartida, aqueles que escondem a presença do mediador contribuem para a mentira romântica (ROCHA, 2009, p.18).

Segundo Girard, há, fundamentalmente, na história do romance duas formas dominantes e que podem se entrelaçar, ou seja, o romance romântico e o romance romanesco. No primeiro tem-se a ocultação da presença do mediador na determinação do objetivo de desejo. Em contrapartida, nos romances romanescos a presença desse mediador é revelada.

De acordo com Pierpaolo Antonello ${ }^{3}$, professor de literatura e cultura italianas na University of Cambridge e profícuo estudioso da obra de René Girad, Italo Svevo é um dos grandes escritores não só do cânone moderno italiano, mas também europeu, que mereceria fazer parte do repertório girardiano acerca dos autores miméticos. Antonello ressalta ainda que na obra do escritor triestino as estruturas do desejo e da imitação representam um amplo sistema de articulação de seus personagens, conforme a prospectiva do filósofo frânces. Consequentemente podemos afirmar que os três romances de Italo Svevo podem ser classificados como obras romanescas, uma vez que a presença do mediador é revelada.

Neste contexto, mentira romântica e verdade romanesca "designam formas diametralmente opostas de lidar com a natureza mimética do desejo": enquanto a primeira omite o mimetismo através da supressão do mediador, a segunda "reflete sobre o desejo mimético através do protagonismo concedido ao mediador" (ROCHA, 2009, p.18).

Girard discorre sobre dois tipos de mediação, a externa e a interna. A mediação externa, segundo ele, ocorre quando não há contato propriamente dito entre sujeito e mediador. Em contrapartida, na mediação interna a distância é reduzida "para que as duas esferas penetrem com maior ou menor profundidade uma na outra" (GIRARD, 2009, p.33). Partindo dessa classificação, podemos dizer que nos romances em análise há o predomínio da mediação interna, portanto não buscaremos exemplos nos textos que ilustrem a mediação externa. Além do mais, o que nos interessa é a relação dos protagonistas com seus potenciais mediadores ou rivais.

\footnotetext{
Artigo intitulado Rivalità, risentimento, apocalisse: Svevo e $i$ suoi doppi, disponível para download em: https://www.academia.edu/2587197/Rivalita_risentimento_apocalisse_Svevo_e_i_suoi_doppi
} 


\section{Revista do SELL}

v. $4, n^{\circ} .2$

ISSN: $1983-3873$

Em Uma vida, o triângulo amoroso é formado por:

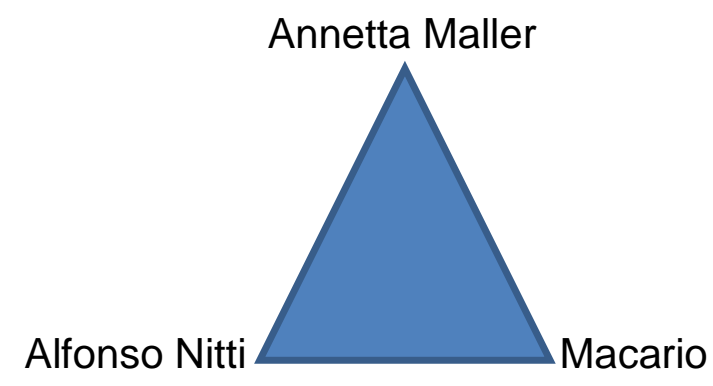

Entre Alfonso e o advogado Macario existe uma relação cordial, uma "amizade" envolta por momentos de intenso contato, certas afinidades e também por distanciamento e repulsa. O senhor Nitti chega a confidenciar suas impressões iniciais sobre a senhorita Maller. O contato próximo entre o protagonista e o advogado indica que tal relação é marcada pela presença da mediação interna.

Característica comum entre os três romances, a descrição física dos mediadores ou rivais é sempre privilegiada se comparada à descrição dos protagonistas. Assim, "o advogado Macario, [é] um quarentão bem apessoado, vestido com extremo apuro, alto e forte e com um rosto moreno cheio de vida..." (SVEVO, 1993, p.39).

Tal descrição, sem dúvida, contribui para a desestabilização e desequilíbrio do protagonista, que além de se sentir inferior, não se acha digno do amor de seu objeto de desejo. Tal premissa justifica-se através da seguinte passagem: "Sentindo-se sempre inferior por causa de sua fala desajeitada, Alfonso tinha violentos ataques de ciúmes, tempestades em copo d'água". (SVEVO, 1993, p.115, grifo nosso). Como podemos notar é evidente não apenas o incômodo que esse rival causa a Alfonso, mas o desencadeamento de seus ciúmes, evidenciado pelos termos grifados.

No segundo romance, os vértices do triângulo serão ocupados pelo protagonista Emilio Brentani, pela sedutora Angiolina Zarri e pelo escultor Stefano Balli, melhor amigo de Emilio: 
Revista do SELL

v. $4, n^{\circ} .2$

ISSN: $1983-3873$

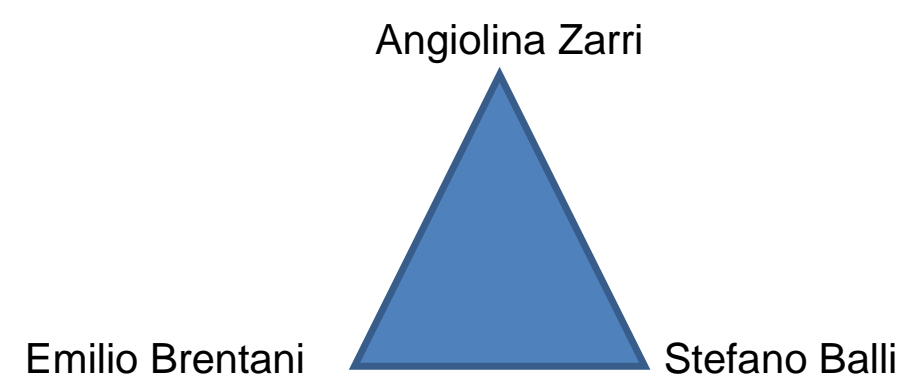

Entre Emilio e Stefano existe uma relação de amizade muito próxima e afetuosa, diferente da relação mais diplomática entre o senhor Nitti e Macario. Para Brentani, Balli é, sem dúvida, seu melhor amigo, mesmo assim demonstra sentir grande ciúme dele. $\mathrm{O}$ contato direto e cotidiano entre eles permite-nos dizer que a mediação nesse caso também é a interna. Assim como Macario, Balli também tem sua descrição enaltecida com traços marcantes:

Stefano Balli era um homem alto e forte, de olhos azuis de criança numa dessas faces de aspecto bronzeado que nunca envelhecem: o único traço da idade era o grisalho dos cabelos castanhos, a barba aparada com precisão, toda a figura muito correta e um tanto dura. Era por vezes doce o seu olhar de observador quando o animava a curiosidade ou a compaixão, mas tornava-se duríssimo na luta ou nas discussões mais fúteis. (SVEVO, 1982, p.19)

A relação harmoniosa que existia entre os dois amigos será estremecida após Emilio apresentar Angiolina ao escultor. Nesse momento, Emilio começa a dar mostras do ciúme que sente do amigo:

- Que mau gosto! - exclamou Balli sem poder deixar de rir. Percebia-se que a partir desse instante Angiolina o divertia muito. Ele continuou a dizerIhe coisas desagradáveis, mas parecia fazê-lo apenas para incitá-la a defender-se. Ela também se divertia com isto. Havia em seu olhar para o escultor a mesma benevolência que brilhava no de Margherita; uma mulher copiava a outra, e Emilio, depois de tentar em vão introduzir algumas palavras na conversa geral, estava agora propenso a perguntar-se por que motivo organizara essa noitada. (SVEVO, 1982, p.69, grifo nosso)

O encontro dos casais que deveria ser de alegria, de prazer termina por causar arrependimento em Emilio, que pretendia mostrar ao amigo sua capacidade em conquistar a bela moça, contudo esqueceu-se de que o amigo era mestre nessa arte, e sempre fazia muito sucesso com o sexo "frágil". Note-se, pelos termos grifados, que o senhor Brentani se sente excluído, e percebe que Angiolina se interessa pelo amigo. $\mathrm{O}$ 


\title{
Revista do SELL
}

v. $4, n^{\circ} .2$

ISSN: $1983-3873$

sentimento amargo que Emilio começa a sentir pelo amigo é confessado por ele mesmo na sequência, quando Balli convida a senhorita Zarri a posar como modelo para uma escultura:

\begin{abstract}
Balli agradeceu e disse que certamente se aproveitaria da oferta, mas somente dali a alguns meses, pois, por ora, estava muito ocupado em outros trabalhos. Fitou-a longamente, imaginando a pose em que a teria retratado, e Angiolina ficou rubra de prazer. Ah, se pelo menos Emilio tivesse um parceiro no sofrimento. Mas, não! Margherita não era de modo algum ciumenta, e também contemplava Angiolina com olhar de artista. Disse que Stefano haveria de fazer um belo trabalho, contando com entusiasmo as surpresas que sua arte lhe havia proporcionado, ao vê-lo extrair da argila dócil uma face, uma expressão, a vida. (SVEVO, 1982, pp.72-73, grifo nosso)
\end{abstract}

Após esse encontro, a relação entre Emilio e Balli não será a mesma. Emilio se afastará do melhor amigo, procurando-o raramente. Brentani tem consciência de seu caráter ciumento, confessando seu grande temor de uma aproximação entre o escultor e Angiolina, de acordo com o excerto:

- Contudo - confessou Emilio sinceramente comovido com o afeto de Balli -, nunca sofri tanto de ciúme quanto agora. - Parando em frente de Stefano, disse-Ihe com voz profunda: - Promete que vai contar-me tudo quanto souber a respeito dela? Não quero que você se aproxime dela, mas se a vir na rua venha logo contar-me. Promete? Promete formalmente? (SVEVO, 1982, p.128, grifo nosso)

Em outros momentos da narrativa, Emilio declara e confessa esse sentimento nefasto que atormenta sua existência; Brentani tem consciência de estar, de acordo com o que nos é descrito, "doente de ciúmes" (SVEVO, 1982, p.129). Ao admitir que sente ciúme de Angiolina, Emilio enfraquece-se enquanto ela fortalece-se, e usa tal confissão a seu favor, estimulando ainda mais o ciúme do amante e divertindo-se com isso.

A hipótese de ver Angiolina com Balli o atormenta, sendo que ele diz preferir ver a amante com qualquer outro homem menos com o amigo. Sabemos pela narrativa que isto não é verdade; Emilio não suportaria ver sua amada com nenhum outro homem, todavia vê-la com o melhor amigo seria uma dupla traição e digamos, dupla privação, pois implicaria na perda do melhor amigo e da mulher amada. 


\section{Revista do SELL}

v. $4, n^{\circ} .2$

ISSN: $1983-3873$

Desse modo, Emilio Brentani é perseguido e torturado com a possibilidade de sua amada se envolver com seu melhor amigo. O próprio Emilio afirma com todas as letras que se Balli não existisse, sua relação com Angiolina seria mais harmoniosa:

Se não fosse ele [BALLI], seu relacionamento com Angiolina teria sido mais suave, não complicado por ciúmes tão amargos. Até mesmo a separação teria sido agora mais feliz. (SVEVO, 1982, p.132, grifo nosso)

Estava mesmo firmado pelo destino que Balli haveria sempre de intervir para tornar mais dolorosa a situação de Emilio em face de Angiolina. (SVEVO, 1982, p.191, grifo nosso)

Tais passagens levam-nos ao questionamento se, de fato, a relação entre Emilio e Angiolina seria mais harmoniosa sem a existência de Balli. A própria narrativa nos permite afirmar que não. Se não fosse Balli a ocupar o terceiro vértice desse triângulo amoroso, certamente, haveria um outro, pois não só o ciúme é intrínseco à natureza do senhor Brentani, que sempre será torturado com a possibilidade da traição, como também o comportamento de Angiolina é duvidoso e questionável.

Importante enfatizar que Senilidade mereceu maior destaque, pois das três narrativas, é a que apresenta o ciúme como tônica central da história. Desse modo, podemos dizer que há uma progressão desse sentimento nos romances analisados. $\mathrm{O}$ ciúme, sem dúvida, começa a ser esboçado no primeiro romance, ganha força no segundo e apresenta-se de maneira mais leve, delineado com certo humor e ironia no terceiro romance, no qual temos o seguinte triângulo:

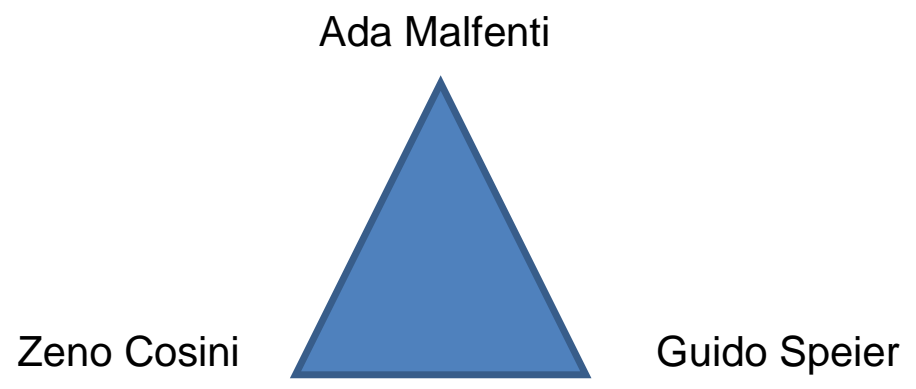

Assim como nos outros dois romances, aqui temos mais um exemplo de mediação interna, pois há contato direto entre o protagonista, Zeno Cosini, e seu rival, Guido Speier. A descrição física do mediador também é enaltecida: 


\section{Revista do SELL}

v. $4, n^{\circ} .2$

ISSN: $1983-3873$

(...) Era um rapaz de muito boa aparência: os lábios naturalmente entreabertos deixavam ver uma boca de dentes brancos e perfeitos. Seus olhos eram vivazes e expressivos e, quando tirou o chapéu, pude ver que seus cabelos escuros e um pouco anelados cobriam todo o espaço que a mãe natureza lhes havia destinado, ao passo que uma boa parte da minha cabeça já fora invadida pela fronte. (SVEVO, 2003, p.98)

Como podemos notar, as descrições dos três rivais assemelham-se bastante, uma vez que as características físicas desses mediadores são fortemente exaltadas. Além de belos, altos, fortes, são bem articulados, sedutores, enfim dotados de atributos que contribuem para gerar a insegurança dos protagonistas e consequentemente, despertar 0 ciúme latente intrínseco a cada um deles.

\section{A RELAÇÃO DO CIÚME COM A FIGURA FEMININA}

Giovanna Miceli Jeffries, ao analisar os romances, Senilidade, de Svevo, e Un amore de Dino Buzzati, ressalta a importância da figura feminina no desencadeamento do ciúme dos protagonistas. Para a crítica o ciúme liga-se ao fascínio físico da mulher (JEFFRIES, 1990, p.360).

Assim como os rivais desses protagonistas, as amadas também apresentam uma descrição física favorável a deixar o sujeito desejante inseguro, sentindo-se não digno do amor de tão belas mulheres. Desse modo, eles tornam-se "presas" fáceis do sentimento amargo que demonstram no decorrer de suas histórias.

Pode-se dizer que tal fascínio físico despertado por tais personagens apresenta ligação direta com a beleza ofuscante das mesmas. Em Uma vida, a princípio, Alfonso parece não prestar atenção à perfeição dos traços de Annetta, mas a convivência maior, ao frequentar a casa da filha de seu patrão, o faz notar a exuberância da senhorita Maller:

Nunca Annetta Ihe parecera tão bonita. Inclinada a escrever, os cabelos escuros e lisos, penteados com simplicidade, a caneta na mão graciosa, via-a pela primeira vez esquecida de sua beleza, sem a preocupação de estar ou não agradando, os lábios apertados, a testa franzida, a cabeça nobre numa atitude nobre. (SVEVO, 1993, p.127) 


\title{
Revista do SELL
}

v. $4, n^{\circ} .2$

ISSN: $1983-3873$

Também em Senildade, a beleza e vitalidade de Angiolina encantam Emilio, que inicia uma aventura amorosa com a moça, esclarecendo-lhe, porém, como já fora ressaltado, que a relação dos dois não passará de um passatempo. O primeiro retrato de Angiolina, como bem observou Beatrice Stasi, limita-se à descrição de seu aspecto físico (STASI, 2009, p.81) Vejamos:

\begin{abstract}
Angiolina, uma loura de grandes olhos azuis, alta e forte, mas esbelta e flexível, um corpo iluminado de vida, uma coloração pálida de âmbar aspergida pelo róseo de uma boa saúde...A mulher o despertara! Radiante de beleza e juventude, deveria iluminá-la toda, fazendo-o esquecer o triste passado de desejo e solidão, e prometendo-Ihe a alegria num futuro que ela, é certo, não haveria de comprometer. (SVEVO, 1982, p.13)
\end{abstract}

Hipnotizado pela perfeição física da moça, Emilio prefere ignorar o passado e a história de vida de Angiolina, com a qual aos poucos entra em contato. Seu interesse maior está em recuperar o tempo "recluso", vivido entre o medíocre trabalho e a convivência com a apática irmã, Amalia. Assim, o protagonista busca entregar-se à sua paixão. Todavia essa entrega é frustrada.

No terceiro romance, A consciência de Zeno, a beleza da mulher amada também é exaltada. Zeno apaixona-se à primeira vista por Ada:

Entraram finalmente Ada e Alberta. Respirei: eram de fato bonitas (...) Ada, ao contrário, já era mulher, com seus olhos sérios numa face que chegava a ser azulada de tão nívea, emoldurada por uma espessa cabeleira, encaracolada, embora disposta com graça e rigor. (SVEVO, 2003, 76)

Como podemos notar, as três mulheres, objeto de desejo desses protagonistas, apresentam características físicas marcantes, que exercem fascínio nos sujeitos desejantes. A propósito desse terceiro romance de Svevo, como já pontuamos, o ciúme é pintado com cores mais leves, cosido com certo humor e ironia. Zeno Cosini é o único protagonista a não ter, a exemplo dos outros dois protagonistas, as migalhas de amor das jovens desejadas, pois sua paixão por Ada não se concretiza. Ela o renega e se casa com Guido Speier, seu rival.

Diante disso, o senhor Cosini casa-se com a irmã da mulher amada, a mais feia segundo ele, todavia o matrimônio lhe traz muitas vantagens e certo equilíbrio para lidar com as situações cotidianas que Alfonso Nitti e Emilio Brentani não apresentam. 


\section{Revista do SELL}

v. $4, n^{\circ} .2$

ISSN: $1983-3873$

Retornando ao fascínio físico exercido pela mulher pode-se dizer que ele atua, juntamente com a descrição física exaltada dos rivais, como mais um elemento no processo de despertar o ciúme nos protagonistas e na impossibilidade de entrega a essas paixões.

\section{CONSIDERAÇÕES FINAIS}

Os três romances de Italo Svevo: Uma vita (1892), Senilidade (1898) e $A$ consciência de Zeno (1923) formam uma trilogia, na qual é bem delineada e aprofundada a análise dos meandros do mais submerso eu da alma. A tríade, de acordo com Teresa de Lauretis, propõe

o mesmo conteúdo de experiência humana: amor não correspondido, dialética empregado-patrão, doença, morte, temas que se organizam em torno e em relação ao Herói, refletindo assim a unicidade de uma experiência individual vista através de lentes diversas e projetadas caso a caso diferentes. (LAURETIS, 1976, p.12, tradução nossa)

A essas três narrativas acrescentam-se um outro conteúdo de experiência humana, isto é, o ciúme, que apresenta-se como o principal protagonista nas histórias e nas relações amorosas dos casais dos romances. Por intermédio da narrativa desses protagonistas notamos a formação e a solidificação do triângulo amoroso, por isso, como bem notou João Cezar de Castro Rocha, ao discorrer sobre o ciúme em Dom Casmurro, de Machado de Assis, poucos exemplos possuem a eloquência de Dom Casmurro, e aqui tomamos a liberdade de incluir os romances de Svevo, ao desenvolver e discutir de forma magistral uma relação amorosa que só consegue existir na presença de um terceiro elemento, um mediador entre o sujeito desejante e seu objeto desejado.

Assim, podemos afirmar que tais narrativas visam ao desenvolvimento e à perscrutação das relações triangulares, fundamentais para a compreensão desses protagonistas. De fato, Alfonso Nitti, Emilio Brentani e Zeno Cosini, não existiriam, não seriam personagens tão bem moldados se desprovidos de seus ciúmes exacerbados. Da mesma forma, as relações amorosas vividas não encontrariam razão para se concretizar, e consequentemente não teríamos o regalo de ler textos intrigantes e envolventes da 
literatura italiana, tecidos com o fino fio das afeições e das aventuras que cada leitor pode encontrar ou enxergar a seu bel-prazer.

\section{REFERÊNCIAS}

ANTONELLO, Pierpaolo. Rivalità, risentimento, apocalisse: Svevo e i suoi doppi.

Disponível

em:

https://www.academia.edu/2587197/Rivalita risentimento apocalisse Svevo e i suoi do ppi. Acesso em: 10 junho 2014.

BARTHES, Roland. Fragmentos de um discurso amoroso; tradução Hortênsia dos Santos. Rio de Janeiro: F. Alves, 1981.

BENVENUTO, Sergio. La gelosia. Bologna: Mulino, 2011.

BORDELOIS, Ivonne. Etimologia das paixões; tradução Luciano. Rio de Janeiro: Odisséia Editorial, 2007.

CLAAR, Micaela Pretolani. Guida alla lettura di Svevo. Arnoldo Mondadori Editore: Milano, 1986.

COLI, Jorge. O lenço e o caos. In: Os sentidos da paixão. NOVAES, Adauto (org.). São Paulo: Companhia das Letras, 2009.

DEBENEDETTI, Giacomo. II romanzo del novecento. Milano: Garzanti, 1987.

GIRARD, René. Mentira romântica e verdade romanesca; tradução Lilia Ledon da Silva. São Paulo: É Realizações, 2009.

Struttura e personaggi nel romanzo moderno.Bompiani: Milano, 1965.

GREIMAS, Algirdas Julien. FONTANILLE, Jacques. Semiótica das paixões: dos estados das coisas aos estados de alma; tradução Maria José Rodrigues Coracini. São Paulo: Editora Ática, 1993. 


\section{Revista do SELL}

v. $4, n^{\circ} .2$

ISSN: $1983-3873$

KLEIN, Melanie. Inveja e gratidão. In: Inveja e gratidão e outros trabalhos (19461963); tradução da $4^{a}$ edição inglesa Belinda H. Mandelbaum et al. Rio de Janeiro: Imago, 1991.

MICELI-JEFFRIES, Giovanna. Per una poetica della senilità: la funzione della donna in Senilità e Un amore. Italica, Vol. 67, No. 3 (Autumn, 1990), pp. 353-370. Published by: American Association of Teachers of ItalianStable URL: http://www.jstor.org/stable/478643.

LAURETIS, Teresa de. La sintassi del desiderio: Struttura e forme del romanzo sveviano. Ravenna : Longo Editore, 1976.

ROCHA, João Cezar de Castro. A primeira pedra de uma catedral. In: GIRARD, René. Mentira romântica e verdade romanesca; tradução Lilia Ledon da Silva. São Paulo: É Realizações, 2009.

SALINARI, C.; RICCI, C.; SERRI, G. II novecento italiano: cultura e letteratura. Roma : Editori Laterza, 1983.

STASI, Beatrice. "Nel mezzo del cammin...”: Senilità. In: Svevo. STASI, Beatrice. Bologna: Mulino, 2009.

SVEVO, Italo. Romanzi e "Continuazioni”. Milano: Mondadori, 2006. . Uma vida; tradução e notas de Aurora Fornoni Bernardini e Homero Freitas de Andrade; prefácio de Augusto Massi. São Paulo: Nova Alexandria, 1993. - Senilidade; tradução de Ivo Barroso. Rio de Janeiro: Nova Fronteira, 1982.

A consciência de Zeno; tradução de Ivo Barroso. Rio de Janeiro: O Globo; São Paulo: Folha de São Paulo, 2003.

VERBARO, Caterina. Senilità. In: Italo Svevo. Soveria Mannelli/Calabria: Rubbettino, 1997. 